\title{
Improve the Three-phase Unbalance Rate of Railway System Under 2\% By Three Kinds of Special Transformer Wiring
}

\begin{abstract}
Author names and affiliations
1. Chien-Hsu Chen : Department of Electrical Engineering, National Cheng Kung University, Taiwan, R.O.C

2. Chin-E. Lin : Department of Aeronautics and Astronautics, National Cheng Kung University, Taiwan, R.O.C
\end{abstract} Corresponding author names and contact details

Chien-Hsu Chen : (e-mail: chsuchen@rb.gov.tw; N28991104@mail.ncku.edu.tw; hsu17972@gmail.com)

\begin{abstract}
Because imbalanced power will cause the loss of the propulsion motor of the railway vehicle, and the increase in temperature will shorten the service life of the electric vehicle. Not only this, but also increase the cost of electricity and maintenance. In the past, the industry only focused on methods to improve power quality such as load capacity, relay setting, and harmonic resolution. Now, the consider of three-phase unbalance rate (TPUR) must be applied. I propose special transformers wiring (STW) to improve the three unbalance rates and provide different transformer wiring methods. According to the IEEE Committee, in the future, power companies will need to install balanced relay stations to improve three-phase unbalance rate. the internal regulations of Taipower must be less than $4.5 \%$ (voltage unbalance rate (NPSUR)of $2.5 \%$ and motor temperature rise of $12.5 \%$ ).

the derivation of the transformer "three-phase unbalance rate" model is the focus of the railway system. This research is based on the model derivation of different wiring methods to improve the hot problem caused by the three-phase imbalance and improve the service life of the train. And pointed out that Scott, Le-Blanc, Modified-Woodbridge three wiring methods can be applied to future railway system routes to improve the three-phase unbalance rate, in line with the IEEE standard of less than $2 \%$.
\end{abstract}

Index Terms - three-phase unbalance rate (TPUR), negative phase sequence unbalance rate (NPSUR), special transformer wiring (STW), Railway System Transport Cable (RSTC), Traction Supply Substation (TSS) 


\section{INTRODUCTION}

The derivation of the transformer "three-phase unbalance rate" model is the focus of the railway system.. In the past, railway system often studied the improvement of harmonic pollution, but ignored the existence of three-phase imbalance. This research is based on the model derivation of different wiring methods to improve the hot problem caused by the three-phase imbalance [1] and improve the service life of the train. And pointed out that Scott, Le-Blanc, Modified-Woodbridge three wiring methods can be applied to future track system routes to improve the three-phase unbalance rate.

The railway transformer power supply mode (as Fig. 1), at present, the transformers used by various countries in the world are not the same. Designing a transformer, the quality of the power, has a great impact on the power supply system [2]. For power companies, voltage unbalance will affect the stability of the system's power supply, leading to increased power consumption, resulting in increased ineffective power consumption and energy waste. Voltage fluctuations, swells or sags will reduce the life of the equipment and increase the temperature, resulting in an increase in the power consumption of the power system. The quality of the transformer has a great impact on the power supply system, and it has to be chosen carefully [3].

According to the IEEE Committee, in the future, power companies will need to install balanced relay stations to improve three-phase unbalance. The imbalance rate is higher than $50 \%$, if the motor continues to operate, the motor will be only half of its life [4]. Therefore, the three-phase unbalance caused by the transformer wiring method has a great relationship with the propulsion power of the railway vehicle. To analysis the voltage unbalance rate, the negative phase sequence unbalance rate of the IEEE specification must be less than $2 \%$ [5], you must start with the three-phase unbalance of the special transformer to see if it meets the voltage unbalance rate of less than $2 \%$ standard. To achieve the purpose of both power saving and efficiency. 


\section{II.HOW TO DEFINE THE VOLTAGE UNGALANCE RATE}

The definition of voltage unbalance rate varies from country to country, and the calculation formulas are also different. In this chapter, three types are proposed for comparison.

1) According to the definition of the National Electrical Manufacturers Association (NEMA):

$$
\operatorname{VUR}(\%)=\frac{\left(V_{3 L}-V_{3 D}\right)_{\text {max }}}{V_{3 D}} * 100 \%
$$

max: maximum $\quad V_{3 \mathrm{~L}}$ : Average value of three-phase line voltage $\quad \mathrm{V}_{3 \mathrm{D}}$ : Average value of three-phase phase voltage

2) According to the definition of Stand 141 of the Institute of Electrical Engineering (IEEE):

$$
\operatorname{VUR}(\%)=\frac{\left(V_{3 L}-V_{3 P D}\right)_{\max }}{V_{3 P D}} * 100 \%
$$

max: maximum $\quad V_{3 \mathrm{~L}}$ : Average value of three-phase line voltage $\mathrm{V}_{3 \mathrm{PD}}$ : Average value of three-phase phase voltage.

3) Defined according to Symmetric Component Analysis (VUF for short):

$\operatorname{VUF}(\%)=\frac{\text { Negative phase sequence voltage component value }}{\text { Positive phase sequence voltage component value }} * 100 \%=\frac{|V 2|}{|V 1|} * 100 \%$ (3)

$\mathrm{V}_{1}$ : Positive sequence voltage component $\mathrm{V}_{2}$ : Negative sequence voltage component $\mathrm{V}_{1} 、 \mathrm{~V}_{2}$ Calculated by Symmetric Component Analysis.

According to IEEE regulations, the three-phase unbalance rate needs to be within $2 \%$, and other calculation formulas can be applied.

$$
\left[\begin{array}{l}
V_{a} \\
V_{b} \\
V_{c}
\end{array}\right]=\left[\begin{array}{ccc}
1 & 1 & 1 \\
1 & a^{2} & a \\
1 & a & a^{2}
\end{array}\right]\left[\begin{array}{l}
V_{0} \\
V_{1} \\
V_{2}
\end{array}\right]\left[\begin{array}{c}
V_{0} \\
V_{1} \\
V_{2}
\end{array}\right]=1 / 3\left[\begin{array}{ccc}
1 & 1 & 1 \\
1 & a & a^{2} \\
1 & a^{2} & a
\end{array}\right]\left[\begin{array}{c}
V_{a} \\
V_{b} \\
V_{c}
\end{array}\right]
$$




$$
\left[\begin{array}{c}
I_{a} \\
I_{b} \\
I_{c}
\end{array}\right]=\left[\begin{array}{lll}
1 & 1 & 1 \\
1 & a^{2} & a \\
1 & a & a^{2}
\end{array}\right]\left[\begin{array}{c}
I_{0} \\
I_{1} \\
I_{2}
\end{array}\right] \quad\left[\begin{array}{c}
I_{0} \\
I_{1} \\
I_{2}
\end{array}\right]=1 / 3\left[\begin{array}{ccc}
1 & 1 & 1 \\
1 & a & a^{2} \\
1 & a^{2} & a
\end{array}\right]\left[\begin{array}{c}
I_{a} \\
I_{b} \\
I_{c}
\end{array}\right]
$$

among them $A=\left[\begin{array}{rrr}1 & 1 & 1 \\ 1 & a^{2} & a \\ 1 & a & a^{2}\end{array}\right]$ Symmetric component matrix, a=1 $\angle 120^{0}$ called Operator.

Therefore $\mathrm{V} 1=1 / 3(\mathrm{Va}+\mathrm{a} 2 \mathrm{Vb}+\mathrm{aVc}) ; \mathrm{V} 2=1 / 3(\mathrm{Va}+\mathrm{aVb}+\mathrm{a} 2 \mathrm{Vc})$.

$a=1 \angle 120^{\circ}=-1 / 2+j \sqrt{ } 3 / 2 ; \quad a^{2}=1 \angle 240^{\circ}=-1 / 2-j \sqrt{ } 3 / 2 ; \quad a^{3}=1 \angle 360^{\circ}=1 ; \quad a^{4}=a$.

\section{DERIVATION OF VOLTAGE UNBALANCE RATE OF SPECIAL TRANSFORMER}

Special transformer wiring is divided into V-V wiring, Scott wiring, Le-Blanc wiring, ModifiedWoodbridge wiring, and Star-Zigzag wiring. Because the electric vehicle is a three-phase unbalanced load, most of the voltage unbalance is caused by the incomplete transposition of the three-phase unbalanced load on the transmission line, so the system unbalance rate is mostly caused by the three-phase unbalanced load. In order to solve this problem, the railway traction power substation can consider using a special transformer wiring method to improve the three-phase unbalance problem [6]. Simplified from Fig. 1 to Equivalent Circuit Fig. 1.

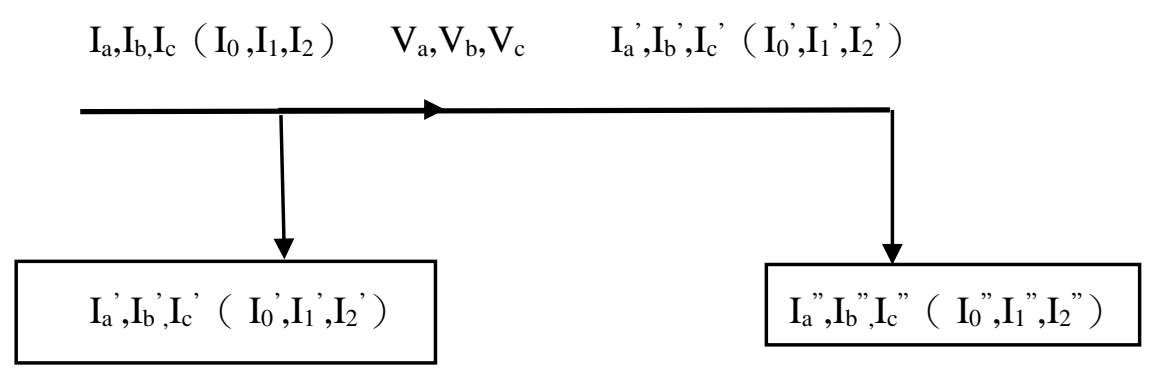

Station substation Traction power substation

Fig. 1. Schematic diagram of transformer equivalent circuit. 
Here we define :

$G_{a}=\left(\frac{N_{2}}{N_{1}}\right)^{2} \frac{1}{R_{a}}, G_{b}=\left(\frac{N_{2}}{N_{1}}\right)^{2} \frac{1}{R_{b}}, G_{c}=\left(\frac{N_{2}}{N_{1}}\right)^{2} \frac{1}{R_{c}}$, among them $R_{a}, R_{b}, R_{c}$ Is the impedance $; \mathrm{N}_{1}, \mathrm{~N}_{2}, \mathrm{~N}_{3}$

Is the turns ;

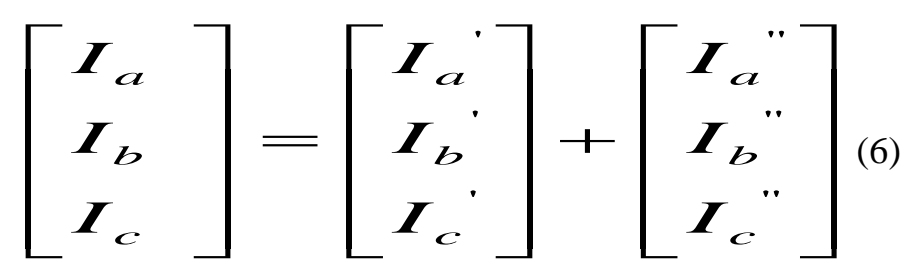

$$
\begin{aligned}
& {\left[\begin{array}{l}
I_{0} \\
I_{2}
\end{array}\right]=\left[\begin{array}{c}
I_{0}^{\prime} \\
I_{1}^{\prime} \\
I_{2}^{\prime}
\end{array}\right]+\left[\begin{array}{c}
I_{0}{ }^{\prime \prime} \\
I_{1}^{\prime \prime} \\
I_{2}{ }^{\prime \prime}
\end{array}\right]} \\
& {\left[\begin{array}{c}
I_{0}^{\prime} \\
I_{1}^{\prime} \\
I_{2}^{\prime}
\end{array}\right]=\left[\begin{array}{lll}
G_{00} & G_{01} & G_{02} \\
G_{10} & G_{11} & G_{12} \\
G_{20} & G_{21} & G_{22}
\end{array}\right]\left[\begin{array}{c}
V_{0} \\
V_{1} \\
V_{2}
\end{array}\right]} \\
& {\left[\begin{array}{c}
I_{a}^{\prime \prime} \\
I_{b}^{\prime \prime} \\
I_{c}^{\prime \prime}
\end{array}\right]=\left[\begin{array}{lrr}
G_{a}+G_{c} & -G_{a} & -G_{c} \\
-G_{a} & G_{a}+G_{b} & -G_{b} \\
-G_{c} & -G_{b} & G_{b}+G_{c}
\end{array}\right]\left[\begin{array}{l}
V_{a} \\
V_{b} \\
V_{c}
\end{array}\right]} \\
& {\left[\begin{array}{l}
I_{0}^{\prime \prime} \\
I_{1}^{\prime \prime} \\
I_{2}^{\prime \prime}
\end{array}\right]=\left[\begin{array}{ccc}
0 & 0 & 0 \\
0 & G_{a}+G_{b}+G_{c} & -a G_{a}-G_{b}-a^{2} G_{c} \\
0 & -a^{2} G_{a}-G_{b}-a G_{c} & G_{a}+G_{b}+G_{c}
\end{array}\right]\left[\begin{array}{l}
V_{a} \\
V_{b} \\
V_{c}
\end{array}\right]}
\end{aligned}
$$

\section{A. Scott Wiring Transformer}

Scott Transformers used in non-grounded systems in England and Japan. The Scott transformer connection method is shown in Fig. 2. 


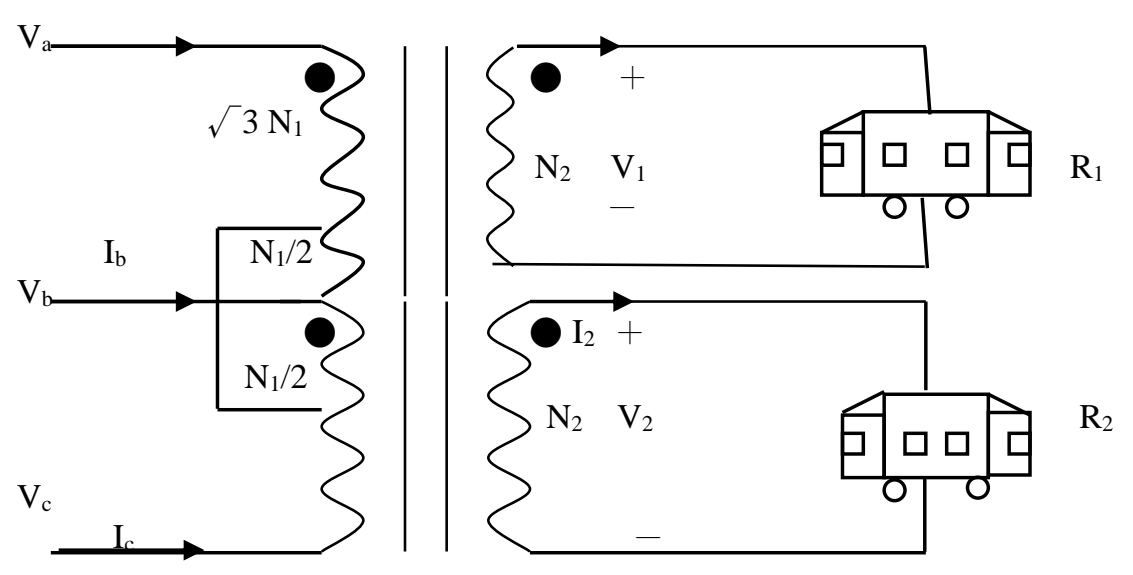

Fig. 2. Scott transformer wiring diagram.

\section{B. Le-Blanc Wiring Transformer}

Le-Blanc transformer is used in German railway system, and its Le-Blanc transformer connection method is shown in Fig. 3.

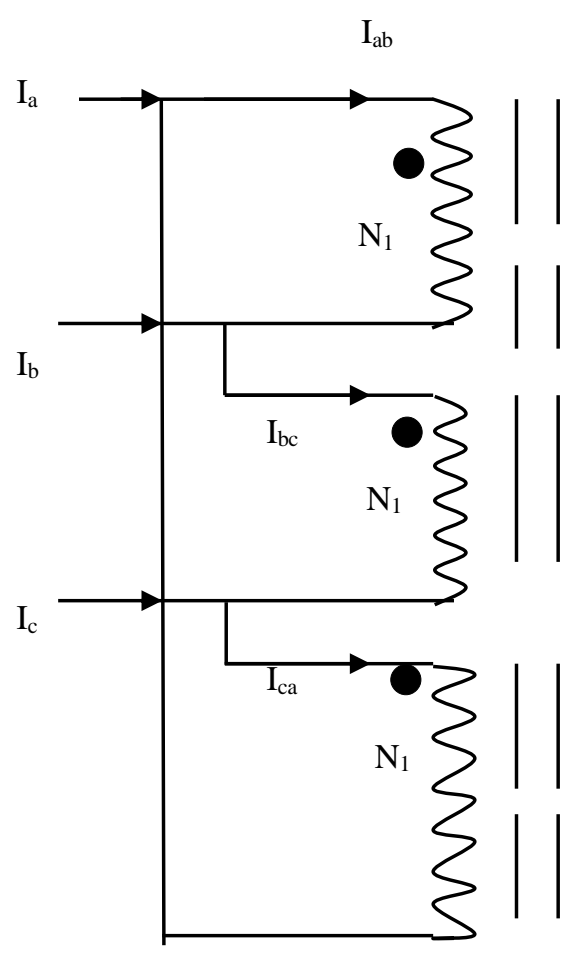

$\mathrm{I}_{1}$

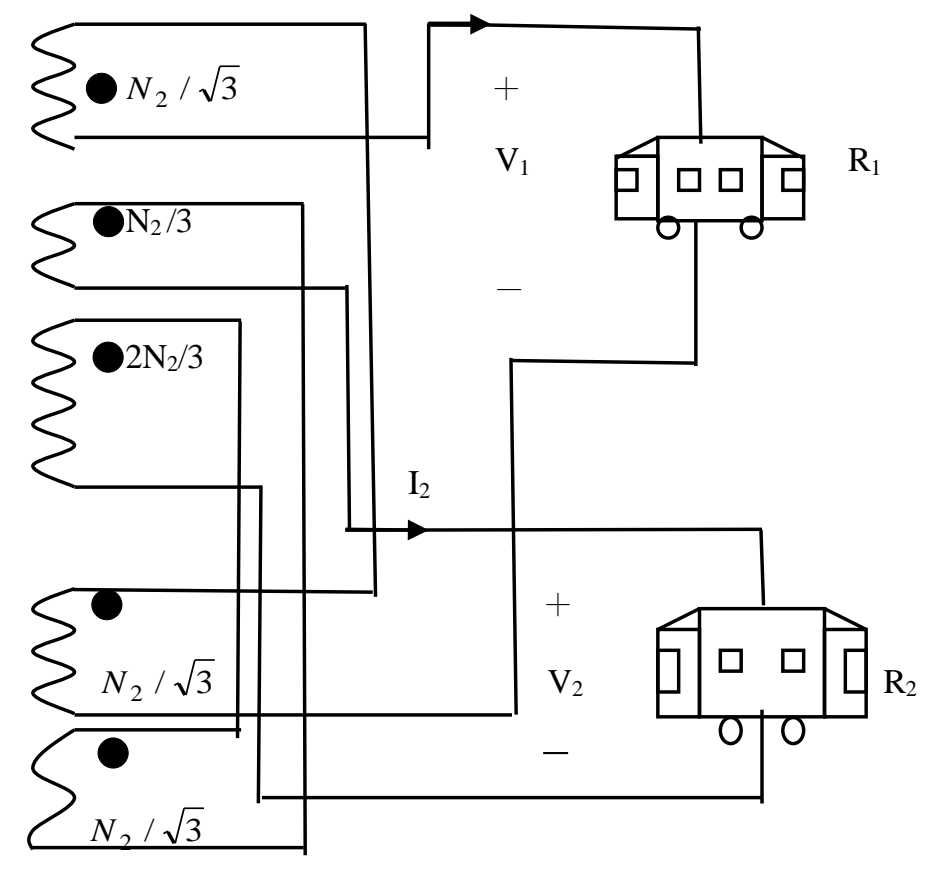

Fig. 3. Le-Blanc transformer wiring diagram. 


\section{Modified-Woodbridge Wiring Transformer}

Modified-Woodbridge transformer is used in Japanese grounding system, and its transformer connection method is shown in Fig. 4.

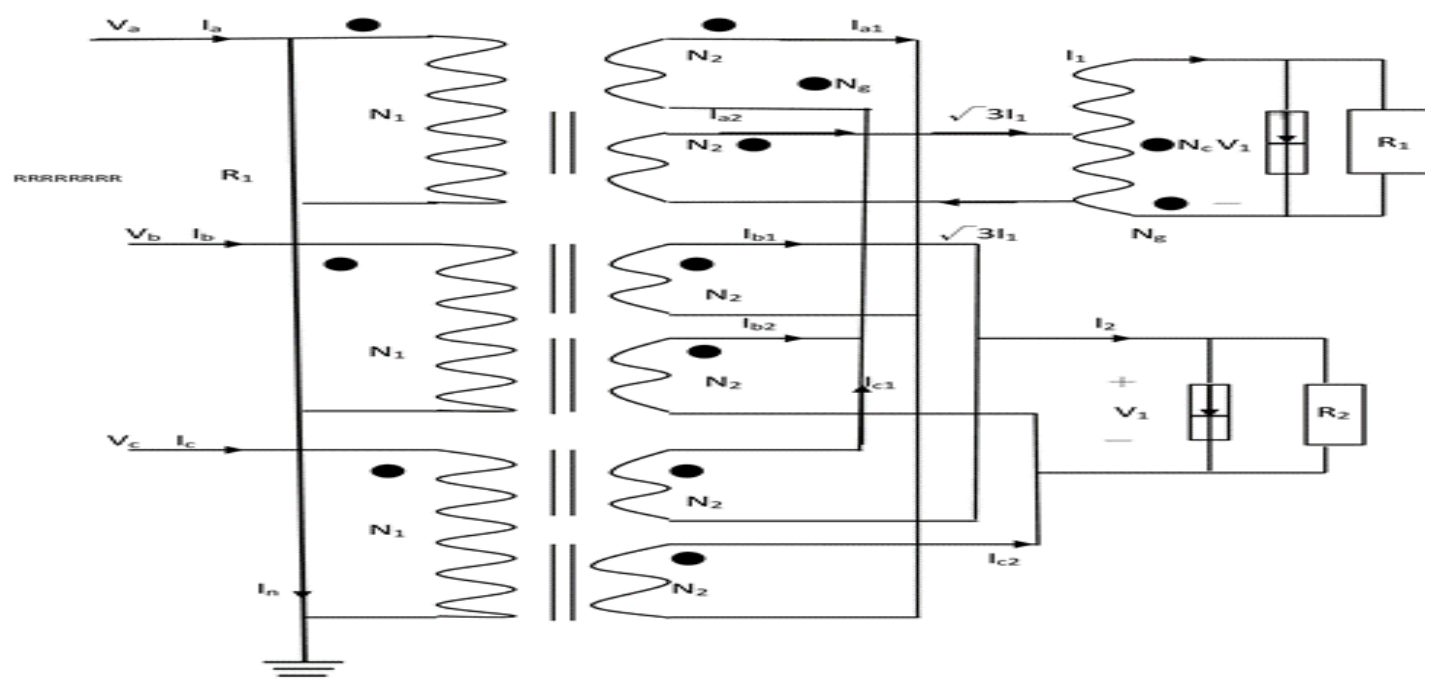

Fig. 4. Modified-Woodbridge transformer wiring diagram among them $\frac{2 N_{g}+N_{c}}{N_{c}}=\sqrt{3}$

\section{RELATIONAL DERIVATION OF THREE SPECIAL WIRING TRANSFORMERS}

\section{A.Scott Wiring Transformer Derivation}

The relationship between Scott wiring transformers calculated according to Fig. 3 is as and from (6)(7):

$$
\begin{gathered}
{\left[\begin{array}{c}
I_{a}^{\prime} \\
I_{b}^{\prime} \\
I_{c}^{\prime}
\end{array}\right]=\left[\begin{array}{ccc}
G_{1} & -G_{1} & 0 \\
-G_{1} & G_{1}+G_{2} & -G_{2} \\
0 & -G_{2} & G_{2}
\end{array}\right]\left[\begin{array}{l}
V_{a} \\
V_{b} \\
V_{c}
\end{array}\right]} \\
{\left[\begin{array}{c}
I_{0}^{\prime} \\
I_{1}^{\prime} \\
I_{2}^{\prime}
\end{array}\right]=\left[\begin{array}{ccc}
0 & 0 & 0 \\
0 & G_{1}+G_{2} & -a G_{1}-G_{2} \\
0 & -a^{2} G_{1}-G_{2} & G_{1}+G_{2}
\end{array}\right]\left[\begin{array}{l}
V_{0} \\
V_{1} \\
V_{2}
\end{array}\right]}
\end{gathered}
$$

among them, $R_{a}, R_{b}, R_{c}$ Is the impedance ; $\mathrm{N}_{1}, \mathrm{~N}_{2}, \mathrm{~N}_{3}$ Is the turns ; $\mathrm{R}_{1=} \mathrm{V}_{1} / \mathrm{I}_{1}, \mathrm{R}_{2}=\mathrm{V}_{2} / \mathrm{I}_{2} ; G_{1}=\frac{1}{R_{1}}, G_{2}=$ $\frac{1}{R_{2}}$.From the three-phase line-to-ground voltage formula (13): 


$$
\left[\begin{array}{l}
0 \\
E_{1} \\
0
\end{array}\right]=\left[\begin{array}{ccc}
R_{0}+3 R_{N} & 0 & 0 \\
0 & R_{E} & 0 \\
0 & 0 & R_{E}
\end{array}\right]\left[\begin{array}{c}
I_{0} \\
I_{1} \\
I_{2}
\end{array}\right]+\left[\begin{array}{l}
V_{0} \\
V_{1} \\
V_{2}
\end{array}\right]
$$

among them

$E_{1}$ : Voltage source positive phase sequence voltage, $R_{p}$ : Self-impedance, $R_{m}$ : Mutual impedance $R_{0}=R_{p}+2 R_{m}$ : Output impedance $R_{N}$ : Neutral impedance $R_{E}=R_{p}-R_{m}:$ Voltage source to ground impedance,

Substituting (10) (11) (12) into (13) gives(15):

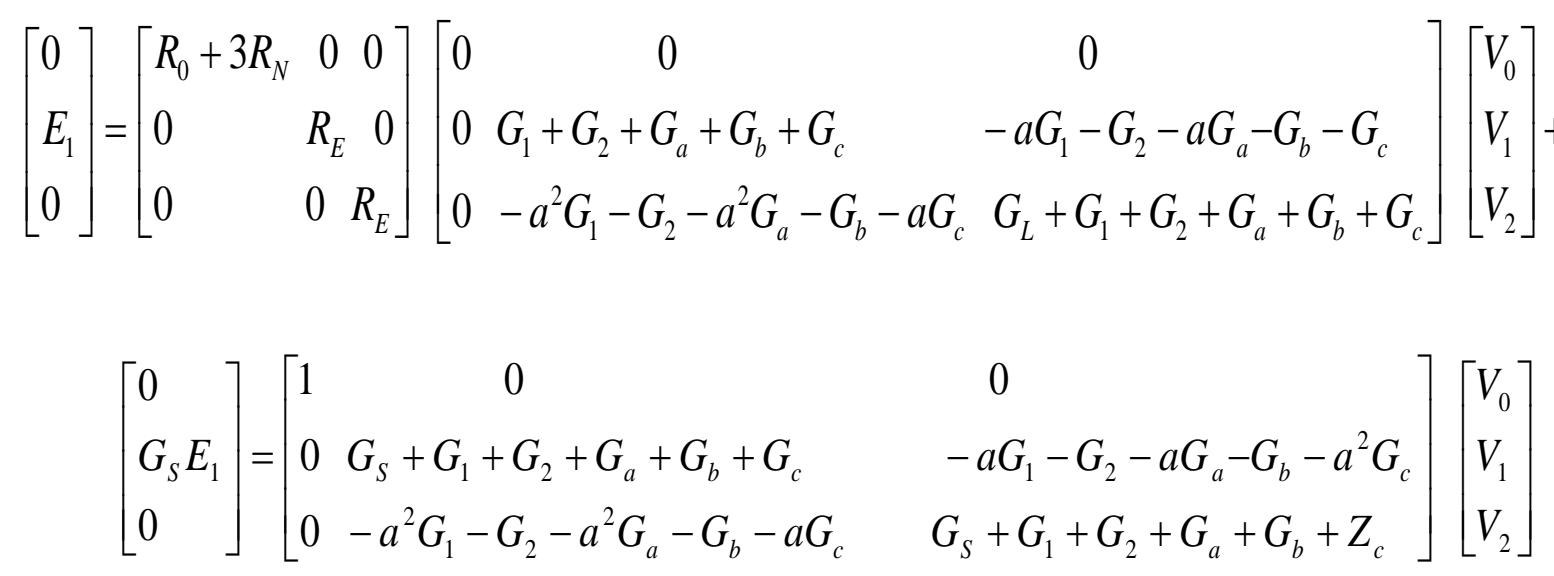

among them $G_{S}=\frac{1}{R_{E}}$ Knowing the three-phase imbalance rate by symmetric component analysis.

$$
\operatorname{VUF}(\%)=\left|\frac{V_{2}}{V_{1}}\right|=\left|\frac{a^{2} G_{1}+G_{2}+a^{2} G_{a}+G_{b}+a G_{c}}{G_{S}+G_{a}+G_{b}+G_{c}+G_{1}+G_{2}}\right|
$$

When the three-phase load is not considered, the three-phase unbalance rate is

$$
\operatorname{VUF}(\%)=\left|\frac{V_{2}}{V_{1}}\right|=\left|\frac{a^{2} G_{1}+G_{2}}{G_{S}+G_{1}+G_{2}}\right|
$$

Important discussion: This situation is likely to be greater than $2 \%$ of the IEEE international standard, which is less suitable for railway TSS power. 


\section{B. Le-Blanc Wiring Transformer Relational Derivation}

The relationship between Le-Blanc wiring transformers calculated according to Fig. 4 is as follows:

$$
\left[\begin{array}{l}
I_{a}{ }^{\prime} \\
I_{b}{ }^{\prime} \\
I_{c}{ }^{\prime}
\end{array}\right]=\left[\begin{array}{ccc}
\frac{4}{3} G_{1} & -\frac{2}{3} G_{1} & -\frac{2}{3} G_{1} \\
-\frac{2}{3} G_{1} & \frac{1}{3} G_{1}+G_{2} & \frac{1}{3} G_{1}-G_{2} \\
-\frac{2}{3} G_{1} & \frac{1}{3} G_{1}-G_{2} & \frac{1}{3} G_{1}+G_{2}
\end{array}\right]\left[\begin{array}{l}
V_{a} \\
V_{b} \\
V_{c}
\end{array}\right]
$$

among them $R_{a}, R_{b}, R_{c}$ Is the impedance ; $\mathrm{N}_{1}, \mathrm{~N}_{2}, \mathrm{~N}_{3}$ Is the turns ; $\mathrm{R}_{1=} \mathrm{V}_{1} / \mathrm{I}_{1}, \mathrm{R}_{2}=\mathrm{V}_{2} / \mathrm{I}_{2} ; \quad G_{1}=$ $\left(\frac{N_{2}}{N_{1}}\right)^{2} \frac{1}{R_{1}}, G_{2}=\left(\frac{N_{2}}{N_{1}}\right)^{2} \frac{1}{R_{2}}$

The three-phase symmetrical component matrix is:

$$
\begin{aligned}
& {\left[\begin{array}{c}
I_{0}{ }^{\prime} \\
I_{1}^{\prime} \\
I_{2}^{\prime}
\end{array}\right]=\left[\begin{array}{ccc}
0 & 0 & 0 \\
0 & G_{1}+G_{2} & G_{1}-G_{2} \\
0 & G_{1}-G_{2} & G_{1}+G_{2}
\end{array}\right]\left[\begin{array}{l}
V_{0} \\
V_{1} \\
V_{2}
\end{array}\right]} \\
& {\left[\begin{array}{c}
I_{0}^{\prime \prime} \\
I_{1}^{\prime \prime} \\
I_{2}^{\prime \prime}
\end{array}\right]=\left[\begin{array}{ccc}
0 & 0 & 0 \\
0 & G_{a}+G_{b}+G_{c} & -a G_{a}-G_{b}-a^{2} G_{c} \\
0 & -a^{2} G_{a}-G_{b}-a G_{c} & G_{a}+G_{b}+G_{c}
\end{array}\right]\left[\begin{array}{l}
V_{a} \\
V_{b} \\
V_{c}
\end{array}\right]}
\end{aligned}
$$

Will Le-Blanc the connection equations (7), (16), and (17) of the wiring transformer are substituted into the three-phase line-to-ground voltage formula (18).

$$
\left[\begin{array}{l}
0 \\
E_{1} \\
0
\end{array}\right]=\left[\begin{array}{ccc}
R_{0}+3 R_{N} & 0 & 0 \\
0 & R_{E} & 0 \\
0 & 0 & R_{E}
\end{array}\right]\left[\begin{array}{l}
I_{0} \\
I_{1} \\
I_{2}
\end{array}\right]+\left[\begin{array}{c}
V_{0} \\
V_{1} \\
V_{2}
\end{array}\right]
$$

Got: 


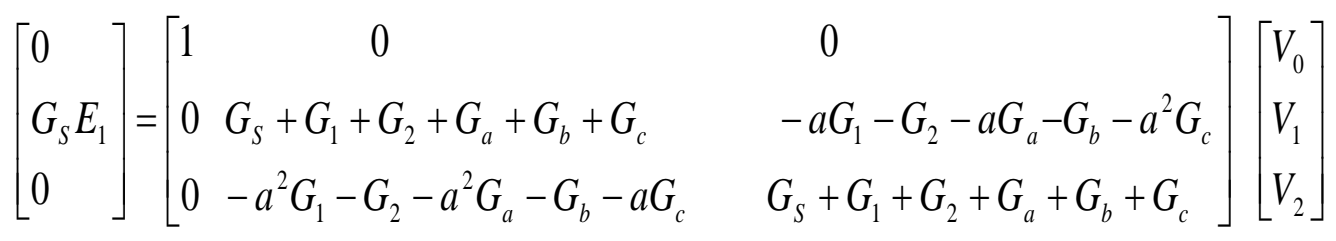

Among them, positive phase sequence voltage of voltage source; self-inductance; mutual inductance; impedance of voltage source to ground;

$$
R_{E}=R_{p}-R_{m} ; G_{S}=\frac{1}{\boldsymbol{R}_{E}}, \text { It is known from the symmetrical component analysis method that the }
$$

three-phase imbalance rate is:

$$
\operatorname{VUF}(\%)=\left|\frac{V_{2}}{V_{1}}\right|=\left|\frac{-G_{1}+G_{2}+a^{2} G_{a}+G_{b}+a G_{c}}{G_{S}+G_{a}+G_{b}+G_{c}+G_{1}+G_{2}}\right|
$$

When the three-phase load is not considered, the three-phase unbalance rate is

$$
\operatorname{VUF}(\%)=\left|\frac{V_{2}}{V_{1}}\right|=\left|\frac{-G_{1}+G_{2}}{G_{S}+G_{1}+G_{2}}\right|
$$

discuss focused on:

Usually $\mathrm{G}_{\mathrm{S}}>>\mathrm{G}_{1}, \mathrm{G}_{2}$, If the denominators $\mathrm{G}_{1}$ and $\mathrm{G}_{2}$ are ignored, then (21) is:

$$
\operatorname{VUF}(\%)=\left|\frac{V_{2}}{V_{1}}\right|=\left|\frac{-G_{1}+G_{2}}{G_{S}}\right|
$$

In this way, GS $>>$ G1, G2, and the molecules are very small, so the three-phase unbalance rate is less than $2 \%$, and the probability is very high. It is one of the ways to consider for traction power substation of MRT.

\section{MODIFIED-WOODBRIDGE RELATIONAL DERIVATION OF WIRING TRANSFORMER}

The relationship between Modified-Woodbridge wiring transformer calculated according to Fig. 5 is as follows: 


$$
\left[\begin{array}{l}
I_{a}{ }^{\prime} \\
I_{b}{ }^{\prime} \\
I_{c}{ }^{\prime}
\end{array}\right]=\left[\begin{array}{ccc}
\frac{3}{4} G_{1} & -\frac{2}{3} G_{1} & -\frac{2}{3} G_{1} \\
-\frac{2}{3} G_{1} & \frac{1}{3} G_{1}+G_{2} & \frac{1}{3} G_{1}-G_{2} \\
-\frac{2}{3} G_{1} & \frac{1}{3} G_{1}-G_{2} & \frac{1}{3} G_{1}+G_{2}
\end{array}\right]\left[\begin{array}{l}
V_{a} \\
V_{b} \\
V_{c}
\end{array}\right]+\frac{1}{3} I_{N}\left[\begin{array}{l}
1 \\
1 \\
1
\end{array}\right]
$$

among them $R_{a}, R_{b}, R_{c}$ Is the impedance ; $\mathrm{N}_{1}, \mathrm{~N}_{2}, \mathrm{~N}_{3}$ Is the turns ; $\mathrm{R}_{1=} \mathrm{V}_{1} / \mathrm{I}_{1}, \mathrm{R}_{2}=\mathrm{V}_{2} / \mathrm{I}_{2} ; \quad G_{1}=$ $\left(\frac{N_{2}}{N_{1}}\right)^{2} \frac{1}{R_{1}}, G_{2}=\left(\frac{N_{2}}{N_{1}}\right)^{2} \frac{1}{R_{2}}$

$$
\left[\begin{array}{l}
I_{0}^{\prime} \\
I_{1}^{\prime} \\
I_{2}^{\prime}
\end{array}\right]=\left[\begin{array}{ccc}
0 & 0 & 0 \\
0 & G_{1}+G_{2} & G_{1}-G_{2} \\
0 & G_{1}-G_{2} & G_{1}+G_{2}
\end{array}\right]\left[\begin{array}{l}
V_{0} \\
V_{1} \\
V_{2}
\end{array}\right]+\frac{1}{3} I_{N}\left[\begin{array}{l}
1 \\
0 \\
0
\end{array}\right]
$$

Substitute the relational expressions (26), (27), and (20) of the Modified-Woodbridge wiring transformer into the three-phase line-to-ground voltage formula (28).

$$
\left[\begin{array}{l}
0 \\
E_{1} \\
0
\end{array}\right]=\left[\begin{array}{ccc}
R_{0}+3 R_{N} & 0 & 0 \\
0 & R_{E} & 0 \\
0 & 0 & R_{E}
\end{array}\right]\left[\begin{array}{c}
I_{0} \\
I_{1} \\
I_{2}
\end{array}\right]+\left[\begin{array}{c}
V_{0} \\
V_{1} \\
V_{2}
\end{array}\right]
$$

Got:

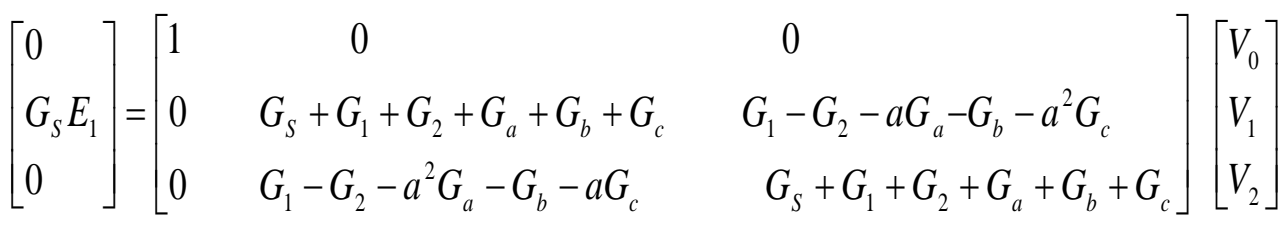

Among them, positive phase sequence voltage of voltage source; self-inductance; mutual inductance; impedance of voltage source to ground;

$R_{E}=R_{p}-R_{m} \quad ; \quad G_{S}=\frac{1}{R_{E}}$

It is known from the symmetrical component analysis method that the three-phase unbalance rate is: 


$$
V U F(\%)=\left|\frac{V_{2}}{V_{1}}\right|=\left|\frac{-G_{1}+G_{2}+a^{2} G_{a}+G_{b}+a G_{c}}{G_{S}+G_{a}+G_{b}+G_{c}+G_{1}+G_{2}}\right|
$$

When the three-phase load is not considered, the three-phase unbalance rate is

$$
V U F(\%)=\left|\frac{V_{2}}{V_{1}}\right|=\left|\frac{-G_{1}+G_{2}}{G_{S}+G_{1}+G_{2}}\right|
$$

discuss focused on:

Usually GS >> G1, G2, if G1 and G2 are ignored, then (31)

Got:

$$
\operatorname{VUF}(\%)=\left|\frac{V_{2}}{V_{1}}\right|=\left|\frac{-G_{1}+G_{2}}{G_{S}}\right|
$$

1) From equations (26) and (16), it can be seen that Scott / Le-Blanc wiring transformer and ModifiedWoodbridge wiring transformer ignore the three-phase load (that is, no-load) and G1, G2. the same.

2) In this way, GS $>>\mathrm{G} 1, \mathrm{G} 2$, and the molecules are very small, so the three-phase unbalance rate is less than $2 \%$, and the probability is very high. It is one of the ways to consider for traction power substation of railway system.

\section{DERIVATION OF VOLTAGE UNGALANCE RATE FOR TRADITIONAL TRANSFORMER AND V-V WIRING STAR-ZIGZAG WIRING}

Traditional transformer wiring is divided into single-phase wiring and three-phase Wye-Delta wiring. Because Taipower adopts a central feeding system, on single-phase wiring transformers, the power source with a feeding point is strong, and the substation also has the favorable factor of small traction load, which is easier in emergency or maintenance. At present, the Taiwan Railway Bureau uses this system. The railway system does not use single-phase wiring transformers because of large harmonic problems and excessive reactive power [7]. 


\section{A. Single-phase Wiring Transformer}

Single-phase wiring transformer is used in Italian railway system, New Zealand railway system, Taiwan railway system, and its transformer connection method is shown in Fig. 5.

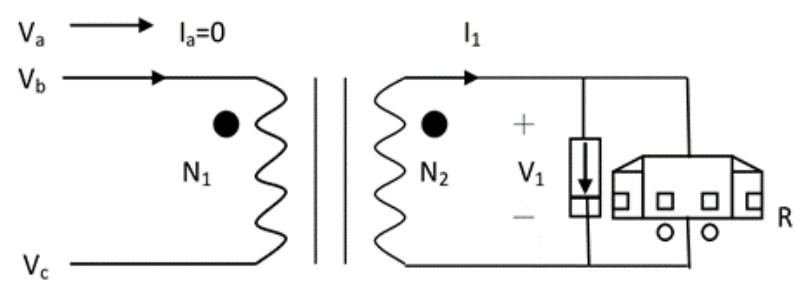

Fig. 5. Wiring diagram of single-phase transformer.

From the calculation in Fig. 5:

In:

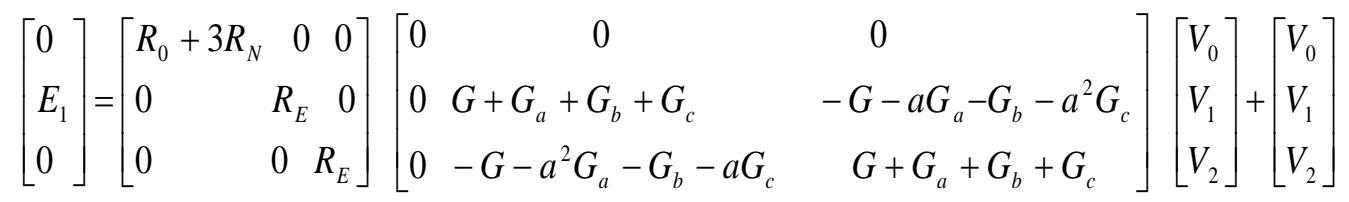

Simplified:

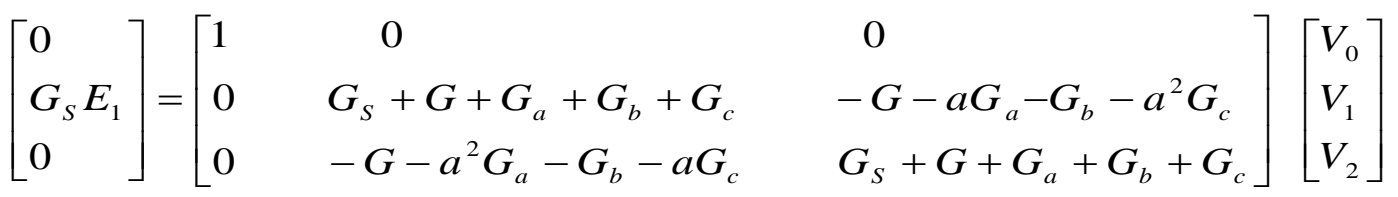

Among them, the symmetric component analysis method shows that the three-phase unbalance rate is:

$$
V U F(\%)=\left|\frac{V_{2}}{V_{1}}\right|=\left|\frac{G+a^{2} G_{a}+G_{b}+a G_{c}}{G_{S}+G_{a}+G_{b}+G_{c}+G}\right|
$$

When the three-phase load is not considered, the three-phase unbalance rate is

$$
\operatorname{VUF}(\%)=\left|\frac{V_{2}}{V_{1}}\right|=\left|\frac{G}{G_{S}+G}\right|
$$


discuss focused on:

Usually GS $>>$ G. If the denominator $\mathrm{G}$ is negligible, then is:

$$
\operatorname{VUF}(\%)=\left|\frac{V_{2}}{V_{1}}\right| \cong\left|\frac{G}{G_{S}}\right|
$$

It is impossible to judge whether the three-phase unbalance rate will exceed the international standard of $2 \%$ under no load [8].

\section{B. Three-phase Wye-Delta Wiring Transformer}

Three-phase Wye-Delta wiring transformers are used in mainland China MRT and railway systems, Taipei MRT Tamsui Xindian line, and the transformer connection method is shown in Fig. 6.

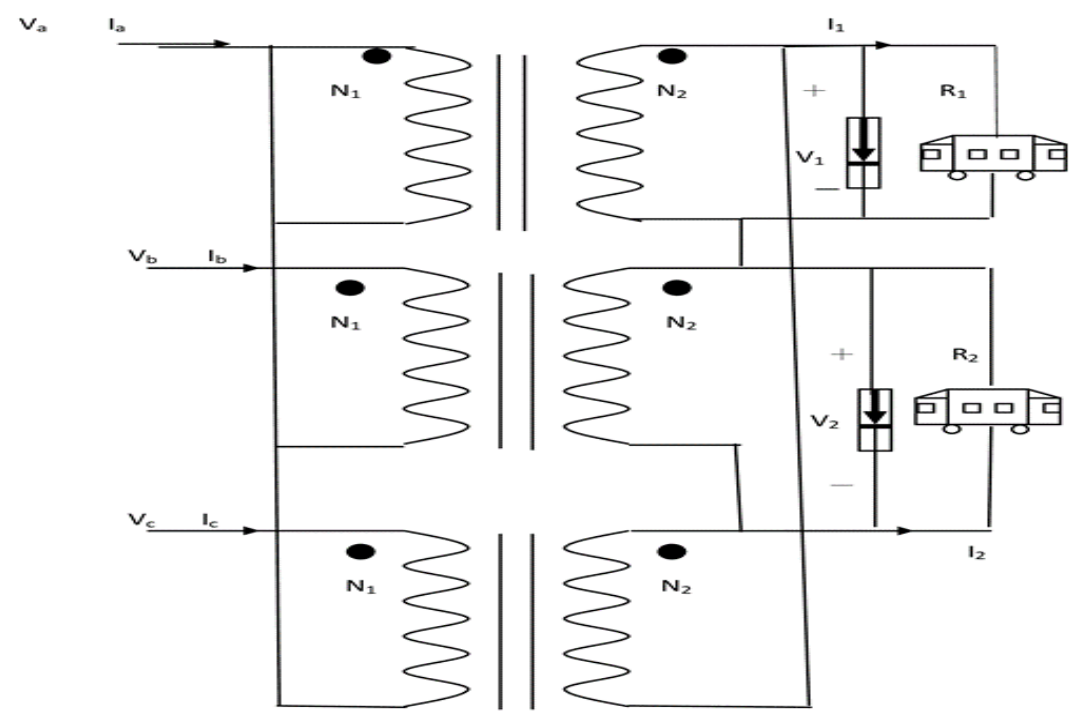

Fig. 6. Wiring diagram of three-phase Wye-Delta transformer.

According to Fig. 6, the three-phase Wye-Delta calculation shows that the relationship of the wiring transformer is as follows: 


$$
\left[\begin{array}{c}
I_{a}^{\prime} \\
I_{b}{ }^{\prime} \\
I_{c}{ }^{\prime}
\end{array}\right]=\left[\begin{array}{ccc}
\frac{3}{4} G_{1}+\frac{1}{3} G_{2} & -\frac{2}{3} G_{1}-\frac{2}{3} G_{2} & -\frac{2}{3} G_{1}+\frac{1}{3} G_{2} \\
-\frac{2}{3} G_{1}-\frac{2}{3} G_{2} & \frac{1}{3} G_{1}+\frac{4}{3} G_{2} & \frac{1}{3} G_{1}-\frac{2}{3} G_{2} \\
-\frac{2}{3} G_{1}+\frac{1}{3} G_{2} & \frac{1}{3} G_{1}-\frac{2}{3} G_{2} & \frac{1}{3} G_{1}+\frac{1}{3} G_{2}
\end{array}\right]\left[\begin{array}{c}
V_{a} \\
V_{b} \\
V_{c}
\end{array}\right]
$$

among them $R_{a}, R_{b}, R_{c}$ Is the impedance ; $\mathrm{N}_{1}, \mathrm{~N}_{2}, \mathrm{~N}_{3}$ Is the turns ; $\mathrm{R}_{1=} \mathrm{V}_{1} / \mathrm{I}_{1}, \mathrm{R}_{2}=\mathrm{V}_{2} / \mathrm{I}_{2} ; G_{1}=$ $\left(\frac{N_{2}}{N_{1}}\right)^{2} \frac{1}{R_{1}}, G_{2}=\left(\frac{N_{2}}{N_{1}}\right)^{2} \frac{1}{R_{2}}$

$$
\left[\begin{array}{c}
I_{0}^{\prime} \\
I_{1}^{\prime} \\
I_{2}^{\prime}
\end{array}\right]=\left[\begin{array}{ccc}
0 & 0 & 0 \\
0 & G_{1}+G_{2} & -a G_{1}-G_{2} \\
0 & -a^{2} G_{1}-G_{2} & G_{1}+G_{2}
\end{array}\right]\left[\begin{array}{l}
V_{0} \\
V_{1} \\
V_{2}
\end{array}\right]
$$

Substitute the relational expressions (35), (36), (17) of the three-phase Wye-Delta wiring transformer into the three-phase line-to-ground voltage formula

$$
\left[\begin{array}{l}
0 \\
E_{1} \\
0
\end{array}\right]=\left[\begin{array}{ccc}
R_{0}+3 R_{N} & 0 & 0 \\
0 & R_{E} & 0 \\
0 & 0 & R_{E}
\end{array}\right]\left[\begin{array}{c}
I_{0} \\
I_{1} \\
I_{2}
\end{array}\right]+\left[\begin{array}{l}
V_{0} \\
V_{1} \\
V_{2}
\end{array}\right]
$$

Got:

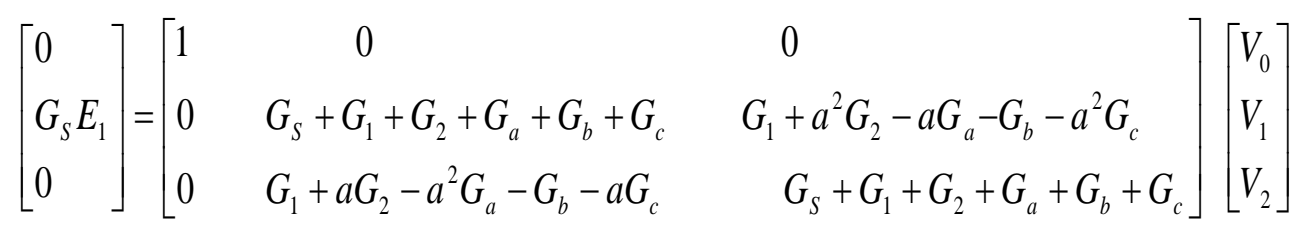

among them

$E_{1}:$ Voltage source positive phase sequence voltage; $R_{p}$ : Self- impedance: $R_{m}$ : Mutual impedance; $R_{0}=R_{p}+2 R_{m}$ : Output impedance, $R_{N}:$ Neutral impedance, $R_{E}=R_{p}-R_{m}:$ Voltage source to ground impedance

It is known from the symmetrical component analysis method that the three-phase imbalance rate is: 


$$
V U F(\%)=\left|\frac{V_{2}}{V_{1}}\right|=\left|\frac{-G_{1}-a G_{2}+a^{2} G_{a}+G_{b}+a G_{c}}{G_{S}+G_{a}+G_{b}+G_{c}+G_{1}+G_{2}}\right|
$$

When the three-phase load is not considered, the three-phase unbalance rate is

$$
\operatorname{VUF}(\%)=\left|\frac{V_{2}}{V_{1}}\right|=\left|\frac{-G_{1}-a G_{2}}{G_{S}+G_{1}+G_{2}}\right|
$$

discuss focused on:

Usually GS >> G1, G2, if the denominators G1 and G2 are negligible, then (38)

Got:

$$
\operatorname{VUF}(\%)=\left|\frac{V_{2}}{V_{1}}\right| \cong\left|\frac{-G_{1}-a G_{2}}{G_{S}}\right|
$$

1) The wiring mode of three-phase Wye-Delta wiring is that the power at the feed point is weak, the substation has a large load, and emergency or maintenance is not easy, but because the MRT station is very short, and there are traction power substations about every two stations. In emergency situations or maintenance, there are 24 hours of personnel on standby, and the replacement of spare parts is fast, which can make up for the shortcomings of the three-phase Wye-Delta wiring in this regard.

2) There is a three-phase imbalance problem in this wiring method. According to the calculation in (43), the molecule has an operator. and it is easy to produce an unbalance rate greater than $2 \%$, so there is room for improvement.

3) Three-phase Wye-Delta wiring produces less harmonics than single-phase wiring [9].

\section{V-V Wiring Transformer}

$\mathrm{V}-\mathrm{V}$ transformer is used in the national railway system of Finland, and its $\mathrm{V}-\mathrm{V}$ transformer connection method is shown in Fig. 7.

$\mathrm{N}_{1} \quad: \quad \mathrm{N}_{2}$




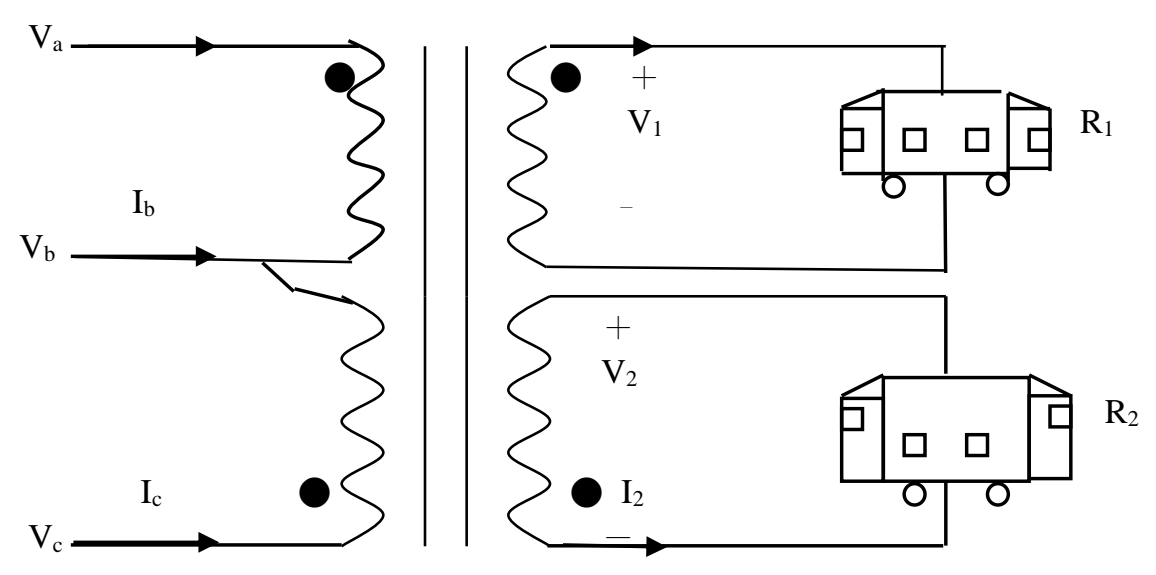

Fig. 7. V-V transformer wiring diagram.

From the calculation in Fig. 7 and from (6)(7):

$$
\begin{aligned}
& {\left[\begin{array}{c}
I_{a}^{\prime} \\
I_{b}{ }^{\prime} \\
I_{c}^{\prime}
\end{array}\right]=\left[\begin{array}{lcc}
G_{1} & -G_{1} & 0 \\
-G_{1} & G_{1}+G_{2} & -G_{2} \\
0 & -G_{2} & G_{2}
\end{array}\right]\left[\begin{array}{l}
V_{a} \\
V_{b} \\
V_{c}
\end{array}\right]} \\
& {\left[\begin{array}{l}
I_{0}^{\prime} \\
I_{1}^{\prime} \\
I_{2}^{\prime}
\end{array}\right]=\left[\begin{array}{ccc}
0 & 0 & 0 \\
0 & G_{1}+G_{2} & -a G_{1}-G_{2} \\
0 & -a^{2} G_{1}-G_{2} & G_{1}+G_{2}
\end{array}\right]\left[\begin{array}{l}
V_{0} \\
V_{1} \\
V_{2}
\end{array}\right]}
\end{aligned}
$$

among them $R_{a}, R_{b}, R_{c}$ Is the impedance ; $\mathrm{N}_{1}, \mathrm{~N}_{2}, \mathrm{~N}_{3}$ Is the turns ; $\mathrm{R}_{1}=\mathrm{V}_{1} / \mathrm{I}_{1}, \mathrm{R}_{2}=\mathrm{V}_{2} / \mathrm{I}_{2} ; G_{1}=\frac{1}{R_{1}}, G_{2}=\frac{1}{R_{2}}$

From the three-phase line-to-ground voltage formula:

$$
\left[\begin{array}{l}
0 \\
E_{1} \\
0
\end{array}\right]=\left[\begin{array}{ccc}
R_{0}+3 R_{N} & 0 & 0 \\
0 & R_{E} & 0 \\
0 & 0 & R_{E}
\end{array}\right]\left[\begin{array}{c}
I_{0} \\
I_{1} \\
I_{2}
\end{array}\right]+\left[\begin{array}{c}
V_{0} \\
V_{1} \\
V_{2}
\end{array}\right]
$$

among them

$E_{1}:$ Voltage source positive phase sequence voltage $R_{p}:$ Self-inductance,

$\boldsymbol{R}_{m}$ : Mutual impedance, $\boldsymbol{R}_{\mathrm{0}}=\boldsymbol{R}_{p}+2 \boldsymbol{R}_{m}$ : Output impedance, $\boldsymbol{R}_{N}:$ Neutral pedance, $\boldsymbol{R}_{E}=\boldsymbol{R}_{p}-\boldsymbol{R}_{m}:$ Voltage source to ground impedance 
Substituting (7), (40), (42) into (43) gives:

$$
\begin{aligned}
& {\left[\begin{array}{l}
0 \\
E_{1} \\
0
\end{array}\right]=\left[\begin{array}{lll}
R_{0}+3 R_{N} & 0 & 0 \\
0 & R_{E} & 0 \\
0 & 0 & R_{E}
\end{array}\right]\left[\begin{array}{lcc}
0 & 0 & 0 \\
0 & G_{1}+G_{2}+G_{a}+G_{b}+G_{c} & -a G_{1}-G_{2}-a G_{a}-G_{b}-G_{c} \\
0 & -a^{2} G_{1}-G_{2}-a^{2} G_{a}-G_{b}-a G_{c} & G_{L}+G_{1}+G_{2}+G_{a}+G_{b}+G_{c}
\end{array}\right]\left[\begin{array}{l}
V_{0} \\
V_{1} \\
V_{2}
\end{array}\right]+\left[\begin{array}{l}
V_{0} \\
V_{1} \\
V_{2}
\end{array}\right]}
\end{aligned}
$$

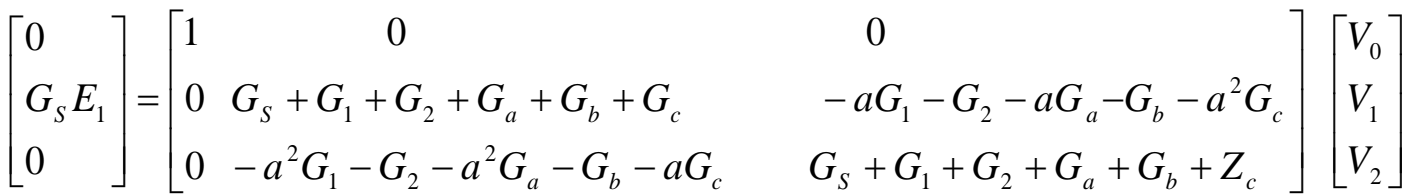

among them $G_{S}=\frac{1}{\boldsymbol{R}_{E}}$ Knowing the three-phase unbalance rate by symmetric component analysis

$$
\operatorname{VUF}(\%)=\left|\frac{V_{2}}{V_{1}}\right|=\left|\frac{a^{2} G_{1}+G_{2}+a^{2} G_{a}+G_{b}+a G_{c}}{G_{S}+G_{a}+G_{b}+G_{c}+G_{1}+G_{2}}\right|
$$

When the three-phase load is not considered, the three-phase unbalance rate is

$$
\operatorname{VUF}(\%)=\left|\frac{V_{2}}{V_{1}}\right|=\left|\frac{a^{2} G_{1}+G_{2}}{G_{S}+G_{1}+G_{2}}\right|
$$

Important discussion: This situation is likely to be greater than $2 \%$ of the IEEE international standard, which is less suitable for power of railway system

\section{Star-Zigzag Wiring Transformer}

Star-Zigzag The transformer is applied to the British subsea tunnel system, and its transformer connection method is shown in Fig. 8. 


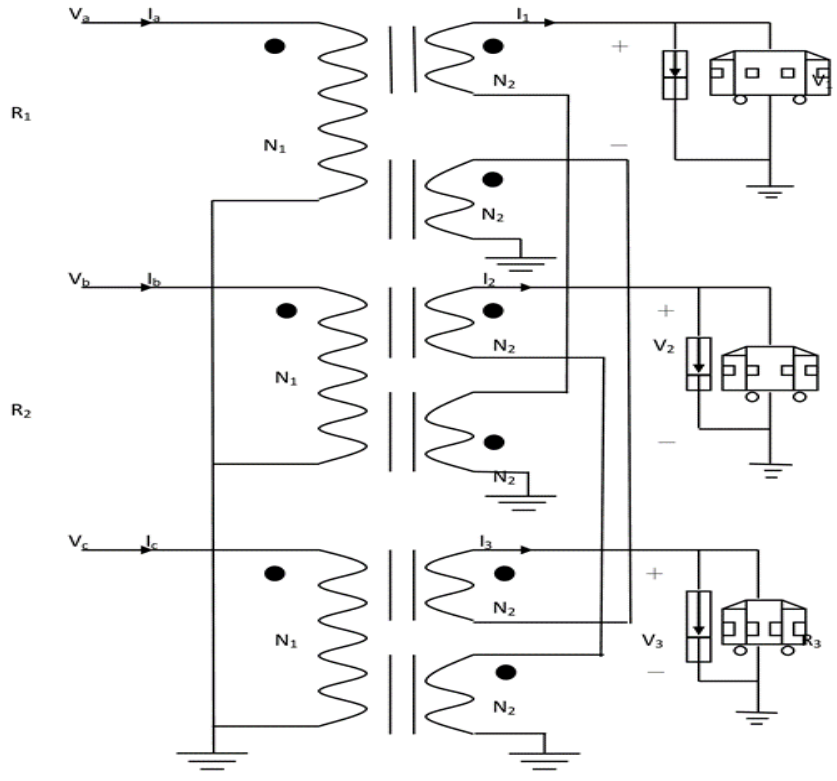

Fig. 8. Star-Zigzag transformer wiring diagram.

The relationship [10] of Star-Zigzag wiring transformer calculated according to Fig. 8 is as follows:

$$
\begin{aligned}
& {\left[\begin{array}{c}
I_{a}{ }^{\prime} \\
\boldsymbol{I}_{b}{ }^{\prime} \\
\boldsymbol{I}_{c}{ }^{\prime}
\end{array}\right]=\left[\begin{array}{ccr}
G_{1}+G_{3} & -G_{1} & -G_{3} \\
-G_{1} & G_{1}+G_{2} & -G_{2} \\
-G_{3} & -G_{2} & G_{2}+G_{3}
\end{array}\right]\left[\begin{array}{l}
V_{a} \\
V_{b} \\
V_{c}
\end{array}\right]} \\
& {\left[\begin{array}{l}
I_{0}^{\prime} \\
I_{1}^{\prime} \\
I_{2}^{\prime}
\end{array}\right]=\left[\begin{array}{ccc}
0 & 0 & 0 \\
0 & G_{1}+G_{2}+G_{3} & -a G_{1}-G_{2}-a^{2} G_{3} \\
0 & -a^{2} G_{1}-G_{2}-a G_{3} & G_{1}+G_{2}+G_{3}
\end{array}\right]\left[\begin{array}{l}
V_{0} \\
V_{1} \\
V_{2}
\end{array}\right]}
\end{aligned}
$$

among them $R_{a}, R_{b}, R_{c}$ Is the impedance $; \mathrm{N}_{1}, \mathrm{~N}_{2}, \mathrm{~N}_{3}$ Is the turns $; \mathrm{R}_{1=} \mathrm{V}_{1} / \mathrm{I}_{1}, \mathrm{R}_{2}=\mathrm{V}_{2} / \mathrm{I}_{2} \quad ; \mathrm{R}_{3}=\mathrm{V}_{3} / \mathrm{I}_{3} ; G_{1}=$ $\left(\frac{N_{2}}{N_{1}}\right)^{2} \frac{1}{R_{1}}, G_{2}=\left(\frac{N_{2}}{N_{1}}\right)^{2} \frac{1}{R_{2}}, G_{3}=\left(\frac{N_{2}}{N_{1}}\right)^{2} \frac{1}{R_{3}}$

Substitute the relational expressions (51), (52), and (20) of the Star-Zigzag wiring transformer into the three-phase line-to-ground voltage formula (59)

$$
\left[\begin{array}{l}
0 \\
E_{1} \\
0
\end{array}\right]=\left[\begin{array}{ccc}
R_{0}+3 R_{N} & 0 & 0 \\
0 & R_{E} & 0 \\
0 & 0 & R_{E}
\end{array}\right]\left[\begin{array}{c}
I_{0} \\
I_{1} \\
I_{2}
\end{array}\right]+\left[\begin{array}{c}
V_{0} \\
V_{1} \\
V_{2}
\end{array}\right]
$$


Got:

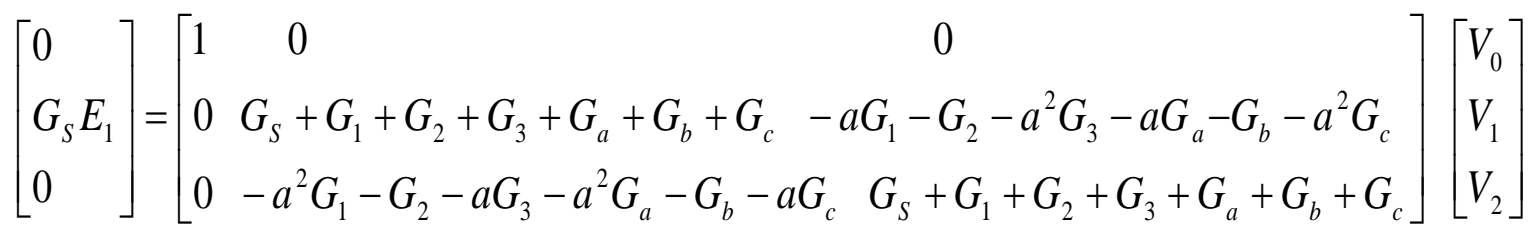

Among them, positive phase sequence voltage of voltage source; self-inductance; mutual inductance; impedance of voltage source to ground;

$$
R_{E}=R_{p}-R_{m} ; \quad G_{S}=\frac{1}{R_{E}}
$$

It is known from the symmetrical component analysis method that the three-phase unbalance rate is:

$$
V U F(\%)=\left|\frac{V_{2}}{V_{1}}\right|=\left|\frac{a^{2} G_{1}+G_{2}+a G_{3}+a^{2} G_{a}+G_{b}+a G_{c}}{G_{S}+G_{a}+G_{b}+G_{c}+G_{1}+G_{2}+G_{3}}\right|
$$

When the three-phase load is not considered, the three-phase unbalance rate is

$$
\operatorname{VUF}(\%)=\left|\frac{V_{2}}{V_{1}}\right|=\left|\frac{a^{2} G_{1}+G_{2}+a G_{3}}{G_{S}+G_{1}+G_{2}+G_{3}}\right|
$$

discuss focused on:

Usually GS >> G1, G2, G3, if the denominators G1, G2, G3 are negligible, then (62)

Got:

$$
\operatorname{VUF}(\%)=\left|\frac{V_{2}}{V_{1}}\right| \cong\left|\frac{a^{2} G_{1}+G_{2}+a G_{3}}{G_{S}}\right|
$$

Important discussion: This involves the angle of the operator. The molecules G1, G2, and G3 cannot be omitted, and the three-phase unbalance rate is easy to exceed $2 \%$, so it is not suitable for power of railway system. 
TABLE I

COMPARISON TABLE OF THREE-PHASE UNBALANCE RATE

\begin{tabular}{|c|c|c|c|c|c|}
\hline & Wiring name & Three-phase unbalance rate under load & $\begin{array}{l}\text { Three-phase unbalance } \\
\text { rate at no load }\end{array}$ & Suitable & Reason \\
\hline \multirow[t]{5}{*}{$\begin{array}{l}\text { Special } \\
\text { transformer } \\
\text { wiring }\end{array}$} & V-V Wiring & $\frac{a^{2} G_{1}+G_{2}+a^{2} G_{a}+G_{b}+a G_{c}}{G_{s}+G_{a}+G_{b}+G_{c}+G_{1}+G_{2}}$ & $\left|\frac{a^{2} G_{1}+G_{2}}{G_{s}+G_{1}+G_{2}}\right|$ & No & $\begin{array}{l}\text { More } \\
\text { than } \\
2 \%\end{array}$ \\
\hline & Scott Wiring & $\frac{-G_{1}+G_{2}+a^{2} G_{a}+G_{b}+a G_{c}}{G_{s}+G_{a}+G_{b}+G_{c}+G_{1}+G_{2}}$ & $\left|\frac{-G_{1}+G_{2}}{G_{s}+G_{1}+G_{2}}\right|$ & Yes & $\begin{array}{l}\text { less } \\
\text { than } \\
2 \%\end{array}$ \\
\hline & $\begin{array}{l}\text { Le Blanc } \\
\text { Wiring }\end{array}$ & $\frac{-G_{1}+G_{2}+a^{2} G_{a}+G_{b}+a G_{c}}{G_{s}+G_{a}+G_{b}+G_{c}+G_{1}+G_{2}}$ & $\left|\frac{-G_{1}+G_{2}}{G_{s}+G_{1}+G_{2}}\right|$ & Yes & $\begin{array}{l}\text { less } \\
\text { than } \\
2 \%\end{array}$ \\
\hline & $\begin{array}{l}\text { Modified } \\
\text { Woodbridge } \\
\text { Wiring }\end{array}$ & $\frac{-G_{1}+G_{2}+a^{2} G_{a}+G_{b}+a G_{c}}{G_{s}+G_{a}+G_{b}+G_{c}+G_{1}+G_{2}}$ & $\left|\frac{-G_{1}+G_{2}}{G_{s}+G_{1}+G_{2}}\right|$ & Yes & $\begin{array}{l}\text { less } \\
\text { than } \\
2 \%\end{array}$ \\
\hline & $\begin{array}{l}\text { Star-Zig Zag } \\
\text { Wiring }\end{array}$ & $\frac{a^{2} G_{1}+G_{2}+a G_{3}+a^{2} G_{a}+G_{b}+a G_{c}}{G_{s}+G_{a}+G_{b}+G_{c}+G_{1}+G_{2}+G_{3}}$ & $\left|\frac{a^{2} G_{1}+G_{2}+a G_{3}}{G_{s}+G_{1}+G_{2}}\right|$ & No & $\begin{array}{l}\text { More } \\
\text { than } \\
2 \%\end{array}$ \\
\hline $\begin{array}{l}\text { Traditional } \\
\text { transformer } \\
\text { wiring }\end{array}$ & $\Delta-Y$ Wiring & $\frac{-G_{1}-a G_{2}+a^{2} G_{a}+G_{b}+a G_{c}}{G_{s}+G_{a}+G_{b}+G_{c}+G_{1}+G_{2}}$ & $\left|\frac{-G_{1}-a G_{2}}{G_{s}+G_{1}+G_{2}}\right|$ & No & $\begin{array}{l}\text { More } \\
\text { than } \\
2 \%\end{array}$ \\
\hline
\end{tabular}

\section{V.CONCLUSION}

According to the calculation method of transformer special wiring and traditional transformer wiring, according to IEEE and international standards, the three-phase unbalance rate is within $2 \%$. We have prepared the following table (such as Table 1) to determine the possibility of reference for future railway system operation

Scott, Le-Blanc, and Modified-Woodbridge have improved the three-phase unbalance problem. This is a good situation, but because it is a special transformer wiring method, there is still little related experience and research, and there is still room for research on the protection of fault current relays. Of course, we hope that the smaller the short-circuit current, the better, and the smoother the power flow distribution.

In this way, the protection relay setting is simpler and the failure rate is smaller. The three usage rates in various countries in the world are not universal, and are generally designed and manufactured by the manufacturers themselves. Therefore, the impedance of the transformer is not a fixed value, and it depends on the material and the number of winding turns. 


\section{REFERENCE}

[1] Liu. S et al., "Practical method for mitigating three-phase unbalance based on data-driven user phase identification," Institute of Electrical and Electronics Engineers Transactions. Power System, vol. 35(2), E pp. 1653-1656, Mar. 2020.

[2] Cummings .P. B., J. R. Dunki-Jacobs, and R. H. Kerr, "Protection of induction motors against unbalanced voltage operation," Institute of Electrical and Electronics Engineers Transaction. Ind. Appl., vol. IA-21(4), pp. 778-792, May 1985.

[3] Tiippana .E , Supply of electricity for electrified lines in Finland. Institute of Electrical and Electronics Engineers Conference. Pub. Int. Conf. Main Line Railway Electrification 1989, Aug. 2002.

[4] Luo. R , Y. He, and J. Liu, "Research on the unbalanced compensation of delta-connected cascaded hbridge Multilevel SVG," Institute of Electrical and Electronics Engineers Transaction on Industrial Electronics, vol. 65, Mar. 2018, pp. 8667-8676.

[5] Jouanne .Annette von, Senior Member, IEEE and Basudeb (Ben) Banerjee, “Assessment of voltage unbalance,” 0885-8977/01, 2001 Institute of Electrical and Electronics Engineers, June 08, 2020.

[6] Zhao X, P. Zhang, H. Tian, and S. Zhao, "Research and practical application of transformer emergency standby calculation and assessment method,” Institute of Electrical and Electronics Engineers, Jan. 2019. [7] Yan. S, S. C. Tan, C. K. Lee, B. Chaudhuri, and S. Y. R. Hui, "Electric springs for reducing power imbalance in three-phase power systems," IEEE Trans. Power Electron., vol. 30, no. 7, pp. 3601-3609, Jul. 2015.

[8] Li. R , C. Gu, F. Li, G. Shad dick, and M. Dale, "Development of low voltage network m .plates-Part I: Substation clustering and classification," IEEE Trans. Power Syst., vol. 30, no. 6, pp. 3036-3044, Nov. 2015.

[9] Ma .K, F. Li, and R. Aggarwal, "Quantification of additional reinforcement cost driven by voltage constraint under three-phase imbalance,” IEEE Trans. Power Syst., vol. 31, no. 6, pp. 5126-5134, Nov. 2016. 
[10] Kong . Z , X. Huang, Z. Wang, J. Xiong, and K. Zhang, “Active power decoupling for submodules of modular multilevel converter," IEEE Trans. Power Electron., vol. 33, no. 1, pp. 125-136, Jan. 2018. 